\title{
Digitalisation Processes and their Impact on the Development of Commodity Trading Companies
}

\author{
Dmitry Zavyalov, Nadezhda Zavyalova, Olga Saginova*, and Natalia Kireeva \\ Plekhanov Russian University of Economics, Department of Entrepreneurship and Logistics, 119997 \\ Moscow, Russia
}

\begin{abstract}
Factors of digitalisation process influencing on stability of the enterprises in sphere of the commodity circulation are considered in the paper. In addition to a significant positive impact in the form of new opportunities for all subjects whose activities are associated with the sphere of commodity circulation, there are many threats that can adversely affect the deformation of market space through the development of digital monopolization.
\end{abstract}

\section{Introduction}

The development of digital technologies has had a significant impact on the processes and business models in the area of commodity circulation, providing stakeholders with new ways to interact. Previously, such interaction was one-way (the company introduced a new product or service to the market, the company formed contractual relations with subcontractors, etc.); now there is feedback from consumers and general information about the reliability and level of competence of potential partners and customers is accumulated in the form of feedback or documents on websites providing comprehensive analysis of companies in the Russian Federation (financial, legal and other) [1, 2].

The perception of competition has changed. Today, companies from different industries are involved in competition or, being competitors in one business area, some companies may cooperate in the IT segment and in other areas [3].

Digital transformation is changing the attitude towards innovation. In the past, innovations were always costly and risky, and the scale of their implementation was severely limited. Nowadays, it is possible to conduct continuous testing and experimentation at the level of low-cost prototypes, and to attract consumers to generate new ideas or test new products.

Modern information and communication technologies influence the business and key areas of business strategies: customers, competition, innovation, and values $[4,5,6]$.

A significant number of publications are based on new opportunities when considering business transformation processes, while new threats also arise in real conditions. The aim of the paper is to consider a complex of factors that influence the development of the sphere of commodity circulation in conditions of active digitalisation of business $[4,5,6]$.

*Corresponding author: $\underline{\text { saginova@yandex.ru }}$ 


\section{Materials and methods}

The study comprises several interrelated parts. The first part is devoted to the analysis of changes taking place in the field of commodity circulation under conditions of total digitalisation; the second part is devoted to the study of the distribution of platform solutions in each of the elements of the commodity circulation system (production, storage, transport, and sale). In their research, the authors relied on thematic scientific publications in journals indexed in Russian and international science and metrics systems, and also on collections of reports from international conferences. For the analysis, data from international statistics were used, which made it possible to see the reflection of digital transformations in the activities of commodity circulation companies.

The analysis of platform solutions proposed to commodity circulation companies is based on open information on the websites of organizations and Internet aggregators, the study of scientific publications, expert speeches in the mass media, materials of public discussions on this topic at conferences and round tables, which made it possible, using general scientific methods (system analysis, comparison, description, generalization, systematization, etc.), to identify, systematize and summarize the most significant factors of the impact of digitalisation on the processes of development and transformations in the field of commodity circulation.

\section{Results and discussion}

\subsection{Changes in the field of commodity circulation as a result of digitalisation}

The development of information technologies and systems has changed the roles of the participants in the field of commodity circulation. They are no longer passive; consumers, suppliers, analytical companies and other entities associated with the commodity supply chain have unlimited opportunities to receive and transfer information. In order to increase the number of customers, marketing services focus not only on persuading them to take an action (buying goods/services), but also on involving them in joint work and helping them improve their goods/services. The flow of values in this process becomes bidirectional (Table 1). Relationships between stakeholders in the commodity sector acquire a cyclical nature and correspond to the phases of Awareness $\rightarrow$ Reflection $\rightarrow$ Need $\rightarrow$ Action $\rightarrow$ Loyalty $\rightarrow$ Assistance $\rightarrow$ Awareness.

Table 1. Changes in commodity circulation from the consumer's perspective.

\begin{tabular}{|c|l|l|}
\hline & Before mass digitalisation & As a result of mass digitalisation \\
\hline 1 & Customers (consumers) - mass market & $\begin{array}{l}\text { Customers - members of an adaptive dynamic } \\
\text { network }\end{array}$ \\
\hline 2 & Main type of communication - advertising & Feedback available \\
\hline 3 & $\begin{array}{l}\text { Customer's estimations are determined by } \\
\text { the companies }\end{array}$ & $\begin{array}{l}\text { Customer's community command the respect of } \\
\text { companies }\end{array}$ \\
\hline 4 & $\begin{array}{l}\text { Marketing is aimed at persuasion to make } \\
\text { a purchase }\end{array}$ & $\begin{array}{l}\text { Marketing is aimed at persuading people to make a } \\
\text { purchase, maintain loyalty and leave a review. }\end{array}$ \\
\hline 5 & Flow of values is unidirectional & Flow of values is bidirectional \\
\hline
\end{tabular}

Source: developed by the authors based on [7].

Companies choose different strategies to interact with customers in the digitalisation of the economy [7]. The access strategy is the most proven and frequently used strategy. 
Companies offer various means of communication and interaction options that make it easier for consumers to access products/goods/services. These include the possibility of purchasing products/goods/services with the help of mobile and stationary devices, an omnichannel front office, on-demand services, and establishing links with entities associated with the activities of the areas of commodity circulation. The success of this strategy is ensured by the simplicity, convenience, accessibility and flexibility of interaction channels. The strategy is substantially aligned with the UN's sustainable development goals, facilitating the transition to sustainable consumption patterns [13].

The communication strategy is focused on providing consumers with new content that can be delivered in a way that attracts the interest of recipients. This can be:

- For trade organisations: (1) a demonstration of a product or service, (2) an emotional video that does not directly characterise a product/service but forces a customer to go to the manufacturer's website to receive a complete information, (3) a presentation of the unique functionality of a product or special service characteristics;

- For transport companies: (1) presentation of safety statistics, (2) demonstration of the quality and capabilities of vehicles, (3) provision of interactive mechanisms for calculating costs directly by the consumer;

- For wholesale and distribution centres: (1) information about services and their cost, (2) product range; (3) software for working together and working through personal offices at various trading platforms.

At present, a consumer is heavily loaded with information. As a result, the majority of advertising messages, both in traditional information channels and social networks, are left without attention and their emotional perception is significantly reduced $[9,10]$. In this case, it is advisable to apply an individualisation strategy that aims to form the most valuable offer to the consumer. This can be an authoritative recommendation, a personal offer of a product/service and a message that takes into account the interests of a consumer and is based on the information actually accumulated in the systems. It should be taken into account that the processing of such data requires an advanced IT infrastructure that allows the accumulation and processing of large volumes of data in various formats. This significantly limits the activities of small and medium-sized companies that do not have the resources to use highly intelligent technologies.

The approval strategy involves close interaction with consumers on the quality and characteristics of goods and services through social networks [11]. The implementation of this strategy requires constant contact with the consumer community in order to answer questions, provide advice and support customers in the event of any problems. Discussion topics can be expanded to include new community members, thus increasing the customer base. The objective of the alignment strategy is to create value. When the company interacts with customers in social networks, the result should be new knowledge about the market and the needs of the customer.

Each of the strategies considered involves the transfer of confidential consumer's information about goods/services, which in a certain situation may not be used in the interests of consumers.

\subsection{Digital solutions and platforms in the field of commodity circulation}

Large technology companies have had a significant impact on the business landscape. For example, in 2009 the list of Top 10 world largest companies by market capitalisation included three oil and gas companies and one technology company (Microsoft Corp.), in 2018 this list included five technology companies and two consumer service companies (Table 2). It should be noted that Amazon.com and Alibaba are both high-tech companies. 
Table 2. The ten largest global companies, 2018. (billion dollars)

\begin{tabular}{|c|c|l|c|}
\hline Place & Company & Industry & Market capitalization \\
\hline 1 & Apple & Technologies & 851 \\
\hline 2 & Alphabet Inc. $^{*}$ & Technologies & 719 \\
\hline 3 & Microsoft Corporation & Technologies & 703 \\
\hline 4 & Amazon.com & Consumer services & 701 \\
\hline 5 & $\begin{array}{c}\text { Tencent Holdings } \\
\text { Limited }\end{array}$ & Technologies & 496 \\
\hline 6 & Berkshire Hathaway & Financial sector & 492 \\
\hline 7 & Alibaba & Consumer services & 470 \\
\hline 8 & Facebook & Technologies & 464 \\
\hline 9 & JPMorgan Chase & Financial sector & 375 \\
\hline 10 & Johnson \& Johnson & Healthcare & 44 \\
\hline
\end{tabular}

Source: United Nations Conference on Trade and Development TD/B/C.I/CLP/54 1 May 2019. Russian URL: https://unctad.org/system/files/official-document/ciclpd54_ru.pdf; PriceWaterhouse Coopers, 2018

* Alphabet Inc. has been the parent company of Google since 2015.

Currently, digital solutions provide a wide range of tools that transform the activities of enterprises participating in the commodity circulation system.

Each of the tools shown in Figure 1 has a positive impact on all areas of sustainable development. When it comes to cargo transportation, algorithms for finding optimal solutions for cargo delivery and picking can reduce cargo transportation costs, ensure cargo safety and timely delivery, and reduce fuel consumption. In the storage of goods, the automation of warehouse management processes has a significant impact on the quality of business processes, which ensures the optimisation of storage costs, increases the speed of loading and unloading operations and frees labour resources from rigging operations. The digital transformation in trade directly contributes to increased customer satisfaction and turnover, and creates conditions for development of small business.

Platform solutions have the greatest impact on the transformation of the merchandise industry[12]. Many of the changes are positive: people and companies have been given opportunities for free communication and choice; access to information is open; and distributed economy services have been implemented, which have an impact on the sustainable development of the economy.

\begin{tabular}{|c|c|c|c|}
\hline Production & Transportation & Storage & Sale \\
\hline \multicolumn{4}{|c|}{ Elements of digital transformation } \\
\hline $\begin{array}{c}\text { Digital } \\
\text { transformation of } \\
\text { production }\end{array}$ & $\begin{array}{c}\text { Digital } \\
\text { transformation of } \\
\text { transport }\end{array}$ & $\begin{array}{c}\text { Digital } \\
\text { transformation of } \\
\text { storage }\end{array}$ & $\begin{array}{c}\text { Digital } \\
\text { transformation of } \\
\text { trade }\end{array}$ \\
\hline \multicolumn{4}{|c|}{ Digital transformation tools } \\
\hline \begin{tabular}{|l|} 
Digital products \\
Digital models \\
Digital business \\
processes \\
Digital management of \\
value chains \\
Industrial cooperation \\
and subcontracting \\
networks \\
Digital platforms
\end{tabular} & \begin{tabular}{|l} 
Optimisation of cargo \\
delivery processes \\
Route planning \\
depending on road \\
load \\
Tracking the location \\
and condition of the \\
cargo \\
Optimisation of staff \\
performance \\
Electronic document \\
management \\
Digital platforms
\end{tabular} & $\begin{array}{l}\text { Warehouse } \\
\text { Management Systems } \\
\text { (WMS) } \\
\text { Technologies of the } \\
\text { Internet of Things } \\
\text { Cobots } \\
\text { Radio Frequency } \\
\text { Identification (RFID)) } \\
\text { Electronic document } \\
\text { management } \\
\text { Digital platforms }\end{array}$ & $\begin{array}{l}\text { Electronic commerce } \\
\text { (B2B, B2C, C2C) } \\
\text { "Smart Shop" } \\
\text { Digital services } \\
\text { Electronic document } \\
\text { management } \\
\text { Digital platforms }\end{array}$ \\
\hline
\end{tabular}

Fig. 1. Digital transformation tools in the field of commodity circulation. 
Thus, from a social point of view, sharing platforms provide the opportunity to receive goods and services much cheaper than in traditional business companies and in a shorter time; they allow to receive additional income by offering services or goods not used for personal consumption. From an environmental point of view, sharing platforms help to reduce the burden on the environment by extending the life cycle of things; sharing cars and tools reduces air pollution.

Until recently, a number of platform solutions in the area of commodity circulation have operated as part of a single activity (e.g. sales, rental, logistics, etc.) or sales models (B2B, $\mathrm{B} 2 \mathrm{C}, \mathrm{C} 2 \mathrm{C})$. Examples of traditional platform solutions in the area of commodity circulation are presented in Table 3.

Table 3. Examples of platform solutions in logistics

\begin{tabular}{|l|l|}
\hline $\begin{array}{l}\text { Platform solutions in the field of } \\
\text { commodity circulation }\end{array}$ & Functions \\
\hline $\begin{array}{l}\text { One transport platform for business Cargolink } \\
\text { (URL:https://cargolink.ru/landing/) }\end{array}$ & $\begin{array}{l}\text { Searching for direct carriers on the map, selecting } \\
\text { cargo for transport companies, informing drivers about } \\
\text { car parks, cafes and feedback about them. Radius of } \\
\text { action 300 km. }\end{array}$ \\
\hline $\begin{array}{l}\text { International shipments online Lardi-Trans } \\
\text { (URL: https://lardi-trans.com/) }\end{array}$ & $\begin{array}{l}\text { Searching for cargo or carrier, adding cargo, } \\
\text { calculating distance, online payment, cargo or vehicle } \\
\text { insurance, information on companies' offers for } \\
\text { business, advertising, industrial services, rental and } \\
\text { lease of special equipment and vehicles, logistics and } \\
\text { warehousing services, sale of automotive equipment, } \\
\text { industrial goods and equipment, food and information } \\
\text { from manufacturing companies }\end{array}$ \\
\hline $\begin{array}{l}\text { The innovative internet platform of FIFA } \\
\text { (URL:https://www.qifa.ru/) }\end{array}$ & $\begin{array}{l}\text { Communication between sellers and manufacturers } \\
\text { from Russia, China and other countries }\end{array}$ \\
\hline $\begin{array}{l}\text { Qoovee platform } \\
\text { (URL:https:/www.qoovee.com/ru/) }\end{array}$ & $\begin{array}{l}\text { Services for the implementation of the B2B segment } \\
\text { business in production, logistics, sales, tender } \\
\text { organisation, etc. }\end{array}$ \\
\hline
\end{tabular}

Source: developed by the authors

In the field of Internet commerce, digital platforms are leading: Avito (https://www.avito.ru/), Price.ru (https://price.ru/), Torg@mail.ru (a Russian-language Internet portal owned by technology company Mail.Ru Group). Yandex.Store, an application store for Android devices, opened by Yandex. Sberbank and Yandex have launched marketplaces Beru (Beru.ru) and Bringly (Bringly.ru) (designed for foreign buyers) and the organizers set themselves the goal of turning YandexMarket into the largest marketplace in Russia For many manufacturers, portal structures (trading platforms) have become a tool for entering the level of international trade. Large trading platforms not only increase their assortment, but also expand the area of fulfilment centres. Sales growth comes from the number of orders, but not from the average check, which has been falling for the third year in a row.

The positive effects of business transformation based on platform solutions include the ability to use distributed resources. By aggregating labour resources, skills, and assets based on platform solutions, it is possible to create new goods / services that are valuable for the consumer. At the same time, partnerships are being formed at the level of digital platforms. The interaction realized within the framework of a single digital space leads to a decrease in the role of hierarchical control systems and an increase in the importance of horizontal links [14].

In addition to the positive manifestation of business transformation processes based on digital platforms, there is a danger of the influence of high-tech companies on the competitive environment. Dominant platforms such as Amazon.com, Apple, and Google 
may own and operate the infrastructure or provide a specific service, that merchants and developers depend on to compete with the service provider in these markets [15].

As in the rest of the world, there are already enough examples in Russia when companies from various business spheres compete. Thus, the Sberbank eco-platform has aggregated a significant number of services, both in the financial segment and in other industries. These include:

- In the segment of selling goods and food: Sbermarket, Sberfood, Samokat, etc ;;

- In the entertainment segment: Ökko, Soyuzmultfilm, Rambler Group;

- In real estate: DomClick, as well as in logistics,

- In the IT segment, and in education.

Entering new markets is typical for many large banking structures. Currently, Tinkoff Bank has integrated financial services (Tinkov Bank, Tinkov Business, Tinkov Investor) and services in the entertainment industry (reservations in hotels and restaurants, theatres, cinema, etc.) into the ecosystem based on platform solutions. The VTB Business-Connect platform presents new opportunities for business (search for buyers, suppliers, sales management of companies, and support for entering international markets. The actions of banking structures to create eco-platforms are explained by the desire of banks to get additional profit when generating new financial flows, the availability of funds for acquisition start-ups or promising companies, as well as financial and technical capabilities for the development of IT solutions

\section{Conclusions}

The development of digital platforms in the field of commodity circulation is still at an early stage. The first experience indicates a number of advantages of using platform solutions for the country's economy. Integration of logistics structures, trade network, and manufacturers allows to ensure the stability of the system of commodity circulation, creates a public environment and conditions for the development of small and medium-sized businesses, promotes the integration of Russian transport into the European and world systems as an equal partner and can significantly affect the growth of non-resource exports while creating a competitive products. At the same time, the dominance of digital platforms can lead to market monopolization and / or aggravation of competition due to the introduction of aggregators into the business for which the platform is formed. The involvement of banking structures can contribute to the deformation of the market space by supporting inefficient enterprises by banks (for example, with the aim of repaying loans), influencing demand by manipulating consumer behaviour, making it more predictable, not always in the interests of consumers themselves. The most dangerous thing is to curb scientific and technological progress. For example, start-ups, under pressure from high-tech companies, are often acquired by dominant platforms. The Federal Antimonopoly Service of Russia has already drawn attention to the trend of takeover of start-ups and the anticompetitive nature of a number of such transactions [16].

There is another side to this problem. In Russia, the digital space in the field of commodity circulation is currently developing by analogy with the offline model - we see a lot of online companies at all stages of the distribution process. In the digital economy, this model can (and already does) lead to a low level of user safety and the safety of personal information. Searching for reliable Internet resources (online stores, service sites, suppliers, consumers, information aggregators) is associated with a significant investment of time and money, and requires a certain client experience to select the most effective and reliable digital platforms.

Thus, market monopolization, on the one hand, and the need to comply with consumer interests and security in terms of storage and use of personal data, on the other hand, are 
risk factors associated with the development of platform solutions. At the moment, at the stage of formation and development of platform solutions in Russia, there is an opportunity to anticipate negative events and amend antimonopoly legislation to exclude unfair competition in the development of platform solutions, as well as formulate requirements for the level of personal data protection and respect for the interests of users. Such an adjustment should contribute not only to the growth of the well-being of the population, but also to the possibility of making a choice of the services used while ensuring privacy, data protection and access to innovation.

The development of platform solutions is undoubtedly the result of technological progress, however, the double impact of digital platforms on the economic environment requires systemic research in the field of commodity circulation with the involvement of experts from both small and medium-sized businesses and large businesses and government agencies. Further studies should consider the possibility and feasibility of applying the existing forms of contractual relations between the companies that own the digital platform (business aggregators) and its users. And although from an economic point of view, digital platforms are technical solutions for the implementation of intermediary activities; negative risks could be reduced by using a sui generis relationship model to agree on the terms of interaction between the business aggregator and platform participants.

The paper was prepared as part of the state assignment of the Ministry of Science and Higher Education No. FSSW-2020-0009 "Development of a methodology for managing the competitiveness of enterprises in the field of commodity circulation in the digital economy".

\section{References}

1 Ponomareva, M. Ponomarev, A. Ponomarev, Advances in Intelligent Systems and Computing, International Conference on Digital Science, 850, 40 (2019)

2 S. Ryu, J. Park, J. of Retailing and Consumer Services, 55, 102094 (2020)

3 G. Surie, Proceedings of the 29th International Conference of the International Association for Management of Technology: Towards the Digital World and Industry X.0, (2020).

4 R. Dornberger, D. Schwaferts, Digital Innovation and Digital Business Transformation in the Age of Digital Change (Book Chapter) Advances in Intelligent Studies in Systems, Decision and Control, 294, 1 (2021)

5 J. Almaazmi, M. Alshurideh, B. Al Kurdi, S.A. Salloum, 6th International Conference on Advanced Intelligent Systems and Informatics, 1261, 731 (2020)

6 V. Ranta, L. Aarikka-Stenroos, J.-M. Väisänen, Digital technologies catalyzing business model innovation for circular economy, Multiple case study Resources, Conservation and Recycling, 164, (2021)

7 D.L. Rogers, Digital transformation. Practical guide, David L. Rogers: Pre. From English, 344 (2017)

8 M. Gorgoglione, U. Panniello, A. Tuzhilin, Information and Management, 56(6), (2019)

9 S.M.C. Loureiro, J. of Promotion Management Volume, 24(2), 198 (2018)

10 J. Mattke, L. Müller, C. Maier, H. Graser, Proceedings of the 2018 ACM SIGMIS Conference on Computers and People Research, 50 (2018)

11 Lang, S. Lang, C. Liu, T. Hang, Malika Nguyen Chaudhuri, International Journal of Research in Marketing, 36(1), 39 (2019) 
12 Case of the Digital Platforms Foundation, December 2017, http://fidp.ru/

13 Monika Schappert, Michael von Hauff, J. of Cleaner Production, 267, 121585 (2020)

14 K. Andreev, Peer-to-peer economy (2019)

15 United Nations Conference on Trade and Development, 54 (2019) https://unctad.org/

16 Acquisitions of startups will fall into the field of view of the FAS, https://fas.gov.ru/ 